\title{
SURGICAL TREATMENT OF INTRACRANIAL ANEURYSMS
}

\section{Six-year experience in Belo Horizonte, MG, Brazil}

\author{
Leodante Batista da Costa Jr1 , Josaphat Vilela de Morais², \\ Agustinho de Andrade 3 Marcelo Duarte Vilela3, \\ Renato P. Campolina Pontes 3 ,Bruno Perocco Braga ${ }^{4}$
}

\begin{abstract}
Spontaneous subarachnoid hemorrhage accounts for 5 to $10 \%$ of all strokes, with a worldwide incidence of 10.5 / 100000 person/year, varying in individual reports from 1.1 to $96 / 100000$ person/year. Angiographic and autopsy studies suggest that between $0.5 \%$ and $5 \%$ of the population have intracranial aneurysms. Approximately 30000 people suffer aneurysmal subarachnoid hemorrhage in the United States each year, and $60 \%$ die or are left permanently disabled. We report our experience in the surgical treatment of intracranial aneurysms in a six year period, in Belo Horizonte, Minas Gerais, Brazil. We reviewed the hospital files, surgical and out-patient notes of all patients operated on for the treatment of intracranial aneurysms from January 1997 to January 2003. Four hundred and seventy-seven patients were submitted to 525 craniotomies for treatment of 630 intracranial aneurysms. The majority of patients were female $(72.1 \%)$ in the fourth or fifth decade of life. Anterior circulation aneurysms were more common $(94.4 \%)$. The most common location for the aneurysm was the middle cerebral artery bifurcation. The patients were followed by a period from 1 month to 5 years. The outcome was measured by the Glasgow Outcome Scale (GOS). At discharge, $62.1 \%$ of the patients were classified as GOS $5,13.9 \%$ as GOS $4,8.7 \%$ as GOS $3,1.7 \%$ as GOS 2 and $14.8 \%$ as GOS 1 .
\end{abstract}

KEY WORDS: aneurysm, subarachnoid hemorrhage, stroke.

\begin{abstract}
Tratamento cirúrgico dos aneurismas intracranianos: experiência de seis anos em Belo Horizonte, MG, Brasil
RESUM 0 - A hemorragia subaracnóidea espontânea é responsável por cerca de 5 a 10\% de todos os acidentes vasculares cerebrais, com uma incidência mundial de 10,5 / 100000 pessoas/ano, variando em estudos individuais de 1,1 a 96 / 100000 pessoas / ano, de acordo com diferenças étnicas e geográficas. Estudos angiográficos e de necropsia sugerem que a presença de aneurismas intracranianos ocorre em 0,5-5\% da população mundial. De acordo com estatísticas norte-americanas, ocorrem cerca de 30000 rupturas de aneurisma cerebral por ano naquele país, com conseqüências desastrosas para grande parte dos pacientes: cerca de $60 \%$ morrem ou permanecem com seqüelas neurológicas graves. Relatamos a experiência do nosso serviço num período de seis anos no tratamento dos aneurismas intracranianos em Belo Horizonte, Minas Gerais. Foram revistos os prontuários e descrições de cirurgia de todos os pacientes operados para tratamento de aneurismas intracranianos no período de janeiro de 1997 a janeiro de 2003. Quatrocentos e setenta e sete pacientes foram submetidos a 525 procedimentos cirúrgicos para tratamento de 630 aneurismas. A maior parte dos pacientes era do sexo feminino, na quarta e quinta décadas de vida. Aneurismas de circulação anterior foram mais freqüentes, e a localização mais comum foi a artéria cerebral média. 0 período de seguimento dos pacientes variou de um mês a 5 anos. A avaliação do resultado foi feita de acordo com a "Glasgow Outcome Scale" (GOS) por ocasião da alta hospitalar, com 296 pacientes em GOS 5 (62,1\%), 66 (13,9\%) em GOS 4, $49(8,7 \%)$ em GOS 3, $8(1,7 \%)$ em GOS 2 e $70(14,8 \%)$ em GOS 1.
\end{abstract}

PALAVRAS-CHAVE: acidente vascular cerebral, aneurisma, hemorragia subaracnóidea.

\footnotetext{
${ }^{1}$ Neurosurgeon, Benjamin Guimarães Foundation and Hospital Evangélico, Belo Horizonte MG, Brazil; ${ }^{2}$ Chief of Neurosurgery, Benjamin Guimarães Foundation and Hospital Evangélico de Belo Horizonte; ${ }^{3}$ Neurosurgeon - Hospital Evangélico de Belo Horizonte; ${ }^{2}$ Resident of Neurosurgery, Benjamin Guimarães Foundation and Hospital Evangélico de Belo Horizonte
}

Received 5 May 2003, received in final form 31 October 2003. Accepted 2 December 2003.

Dr. Leodante Batista da Costa Jr - Rua Três Corações 13/302 - 30480-110 Belo Horizonte M G - Brasil. 
Intracranial aneurysmal rupture hemorrhage is a devastating event, with an estimated mortality of $45 \%$ and a high morbidity (25-33\%). The estimated prevalence of intracranial aneurysms worldwide is 10,5 / 100000, varying according to ethnic and geographic characteristics. Angiographic and autopsy studies suggest that $0.5-5 \%$ of the population harbor intracranial aneurysms. Our service is responsible for the neurosurgical assistence in two hospitals in Belo Horizonte, Minas Gerais, serving an area of approximately 3500000 people in a great metropolitan area. The neurosurgical services in Belo Horizonte are also responsable for the more complex neurosurgical care of patients referred from all over the state. These two hospitals are foundations, and the majority of the patients admitted are covered by the public health system.

In the last years, our hospitals are receiving an increasing number of patients with ruptured and unruptured intracranial aneurysms, and we were able to see a proportionally higher number of patients with high Hunt Hess scale among them. Due to this increasing number of aneurysm surgery in the last years, we have decided to evaluate our results, with special attention to the mortality rate and overall Glasgow Outcome Scale (GOS) at discharge.

\section{METHOD}

We review ed the hospital files, surgical and out-patient notes of all patients operated on in one of our two hospitals for the treatment of intracranial aneurysms from January 1997 to January 2003. Only saccular aneurysms were considered; mycotic, traumatic and fusiform aneurysms were excluded. Patients with subarachnoid hemorrhage who w ere not operated either because of very poor grade or rebleeding and death while waiting for surgery were also excluded.
The clinical condition was evaluated at admission based on the Hunt Hess scale, and the CT scan aspect of the bleeding was graded according to the Fisher scale. The outcome was measured by the Glasgow Outcome Scale, at the hospital discharge. The patients were followed by a period from 1 month to 5 years. It is well known that a significant porcentage of these patients improve significantly in few months after surgery, but the option for evaluating them at discharge was made to avoid losing them at follow up.

\section{RESULTS}

Four hundred and seventy seven patients were submitted to 525 operations for treatment of 630 intracranial aneurysms, in a six-year period, in two hospitals served by the same neurosurgical team. (Figs 1,2 ) The majority of patients were female $(72.1 \%)$ in the fourth or fifth decade of life. Medium age was 47,3 years, with the youngest patient being 11 years old, and the oldest 83 years old. Most (more than $60 \%$ ) were admitted in good grades (I and II) according to Hunt-Hess scale, and overall good GOS scales, defined as 4 or 5 , were obtained at discharge in $76 \%$ of the patients (Fig 3 ). The incidence of multiple lesions was similar to the literature, but the location of the aneurysms was not. Anterior circulation aneurysms were much more common, corresponding to $94,4 \%$ of cases. The most common location for the aneurysm was the middle cerebral artery bifurcation, with 205 aneurysms operated in this location (32,5\%), followed by internal carotid/posterior communicating artery $(24,6 \%)$ and anterior communicating artery $(17,5 \%)$. In the posterior fossa, the most common location was the basilar tip, with 16 lesions $(3,1 \%)$ followed by the proximal posterior inferior cerebellar artery, with 12 lesions $(1,7 \%)$. The anatomical locations of the lesions are showed in

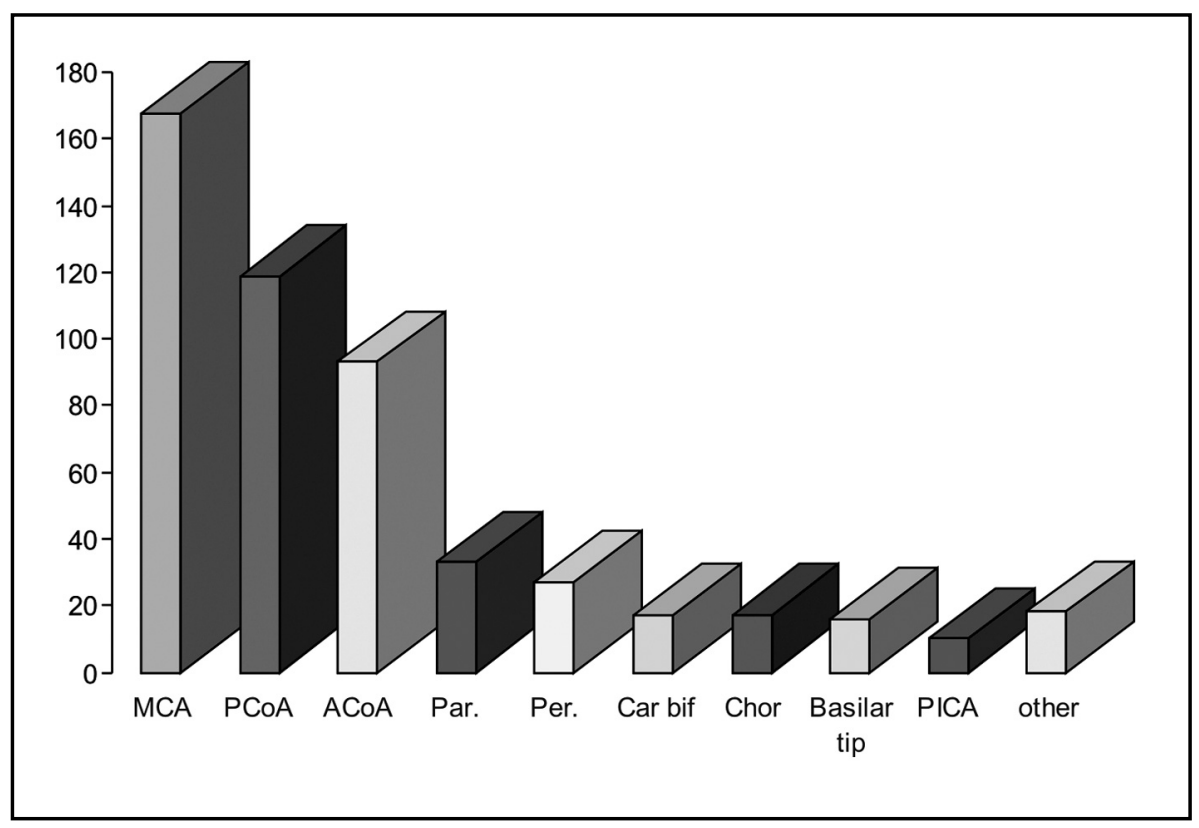

Fig 1. Proportional anatomical location of the lesions. 


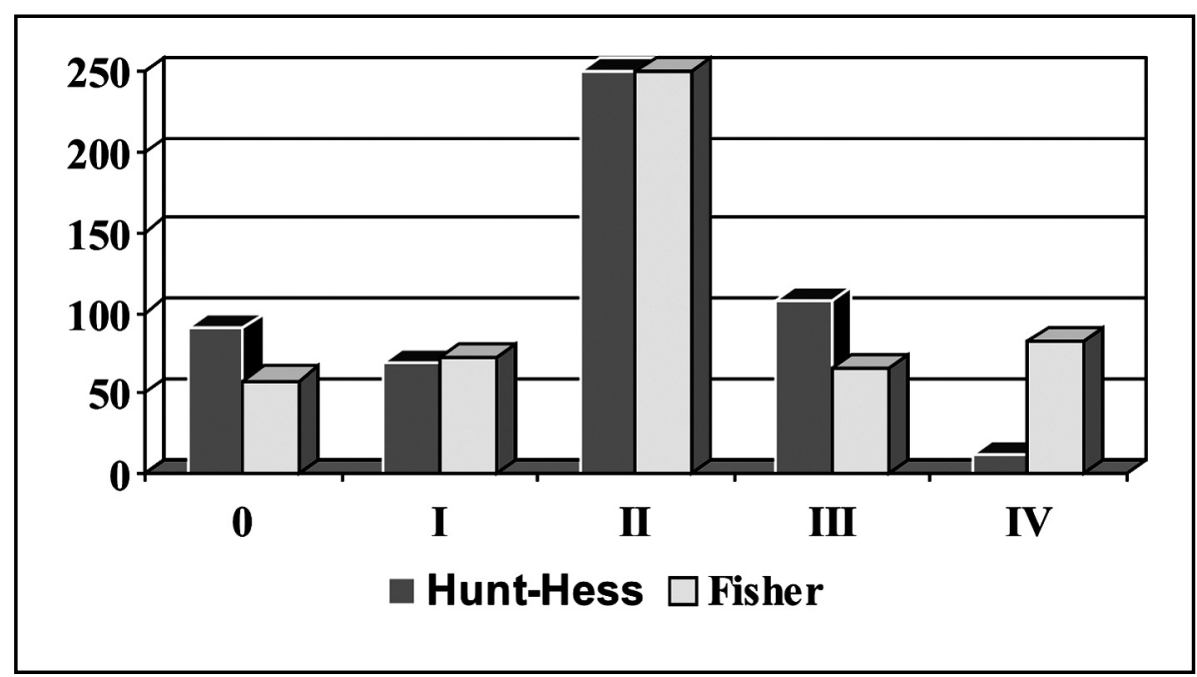

Fig 2. Distribution of the patients according to Hunt-Hess and Fisher distribution.

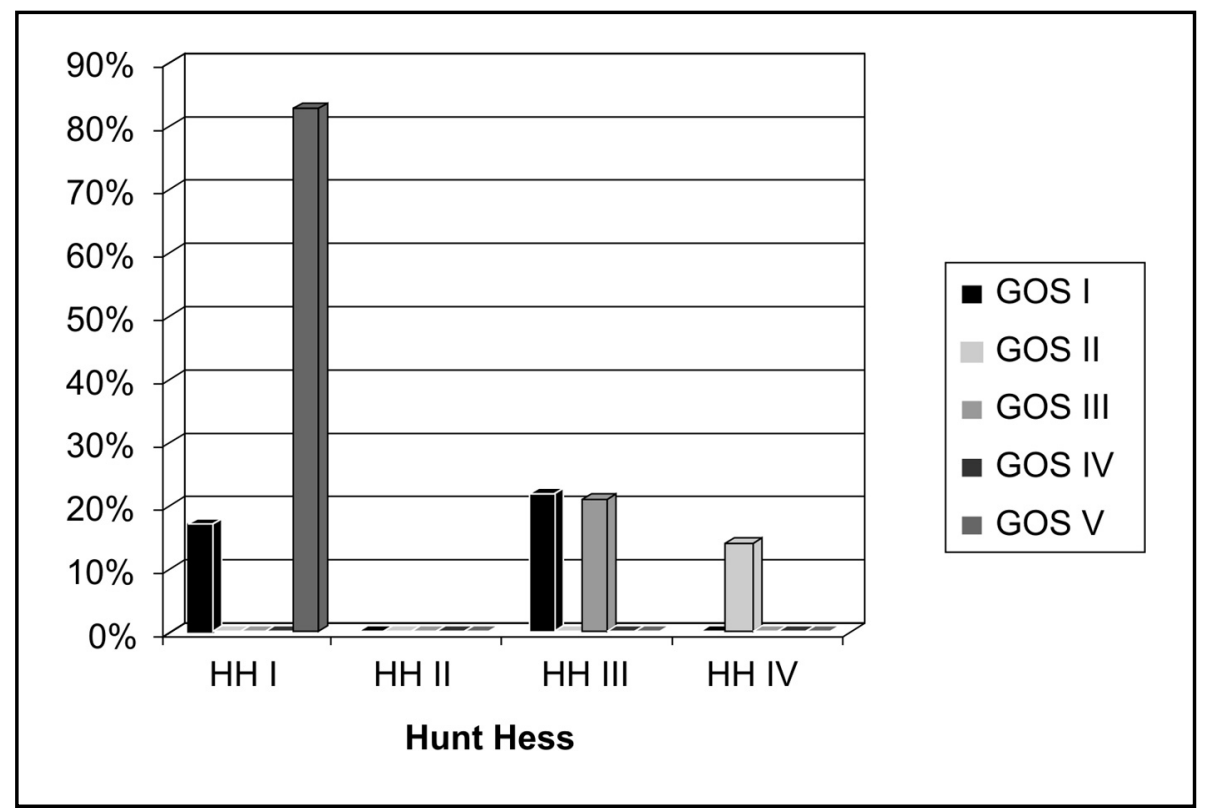

Fig 3. Correlation between Hunt-Hess scale at admission and GOS at discharges.

Figure 1. We were not able to explain why we have more middle cerebral artery aneurysms in our series. Maybe the close association of our hospitals with a regional Emergency Service made easier the referral of patients with hematomas following rupture of middle cerebral lesions. At discharge, most of the patients were able to return to their previous activities. According to the Glasgow Outcome Scale, $62,1 \%$ of the patients were classified as GOS 5, 13,9\% with GOS 4, 8,7\% with GOS 3, 1,7\% with GOS 2 and $14,8 \%$ GOS 1 .

\section{DISCUSSION}

Despite the great evolution in the diagnostic tools, critical care, and the advances in microanatomy and microneuro- surgery, intracranial aneurysms are still a major cause of death and disability in neurosurgical practice even in great international referral centers for neurovascular surgery. Nontraumatic subarachnoid hemorrhage accounts for nearly $5 \%$ to $10 \%$ of all strokes, and the vast majority of these hemorrhages are caused by ruptured intracranial aneurysms. Angiographic and autopsy studies suggest that between $0.5 \%$ and $5 \%$ of the population have intracranial aneurysms, and the annual incidence of rupture in patients with known aneurysm is 1.4\% to $2.3 \%$. Major series relate high mortality and morbidity rates, with a 60 -day mortality greater than $50 \%$ and more than one-third of victims suffering permanent disability ${ }^{1-6}$. Due to the limited resources for health care in developing countries, 
these numbers could be even worse in our country.

Our institutions are involved in the care of a great part of the patients with neurosurgical diseases in a metropolitan area of aproximately 3500000 people, receiving also patients from all over the state and also some from other parts of the country. Nowadays we perform approximatelly 130 neurosurgical procedures/month, with 8 to 10 craniotomies for intracranial aneurysms each month. Almost all neurovascular procedures are performed by the same authors (LBCJ, JVM , AA, MDV).

Patients with a suspected spontaneous subarachnoid hemorrhage are managed in our institutions according with established protocols: urgent computerized tomography (CT) scan, angio-CT or angiography, no antihypertensive drugs unless extremely necessary (SBP > 200), hyperhidration and hypervolemia, urgent surgery if in good grade (Hunt-Hess I or II) or in poor grade (III or IV) with hematoma, ventriculostomy if needed ${ }^{7-9}$. We do have some limitations concerning endovascular resources, mostly because of characteristics of the brazilian public health system; this policy are changing over the time, but we are surelly far from ideal in this field.

In the beginning of this series, almost all craniotomies were delayed at least 10 days because of referral patterns, since the majority of the patients were admitted with more than 5 days of bleeding, making surgical treatment in the acute fase more difficult. Changes occurred and nowadays most patients are admitted in the first days following bleeding, with almost all of them operated as soon as possible after admission, unless there is overt vasoespasm, very poor grade (without hematoma or hydrocephalus), a posterior fossa and/or giant aneurysm or a severe medical illness that precludes surgery.

Most of the patients were admitted in good grades (I and II) according to Hunt-Hess scale. The number of patients admitted in poor grades are increasing over time, maybe because of increasing direct referral of patients in poor neurosurgical condition to our hospitals.

All patients with subarachnoid hemorrhage are submitted to angiography or angiotomography as soon as possible after admission, managed in a semi-intensive neurosurgical unit with moderate hypervolemia and hypertension, adequate analgesia and light sedation and anticonvulsive medications. Surgery was schedule in the next operative day on an urgent basis, unless in patients with hematoma and or hydrocephalus, that were operated imediatelly.Ventriculostomy was performed in all poor grade patients ( Hunt-Hess III and IV) with or without overt hydrocephalus.

At discharge, most patients were able to resume previous ativities, with Glasgow Outcome Scale of 5 or 4 in $76 \%$ of the patients. We noted in the follow up period that a significant number of patients in GOS 4 and 3 improved, some with complete recovery. None of the patients severely disabled (GOS2) improved. We were surprised with the high mortality rate in Hunt-Hess 0 patients - unruptured aneurysm - and Hunt-Hess I. We attributed this to the significant number of giant and paraclinoid aneurysms in this group of patients, presenting with mass effect or visual compromise, which for us were more technically demanding.

The International Cooperative Study on the Timing of Aneurysm Surgery, with 2922 patients operated for treatment of ruptured aneurysms in 68 centers in the world, mostly in the United States, reported a mortality of $14 \%$, with $69 \%$ of "good results", and Osawa et al. reported 2055 patients treated in Japan in a ten-year period, with $12.9 \%$ of mortality (GOS 1 ), and $68.5 \%$ of "excellent and good results". Analysing our results, we found them very similar to these mentioned above and to another in the literature, including a small brazilian series, with 100 patients ${ }^{10-13}$. Considering the differences in the amount of resorces for health care systems in developed and developing countries, we think were nicely surprised with this results. When we think about the whole number of patients sufering from aneurysm subarachnoid hemorrhage in our region, it's almost certain that a great number of patients could be saved if the prehospital care and referral systems were more organized. However, considering only those patients admitted to specialized medical treatment, we think that it's possible to achieve results very similar to those published worldwide.

\section{CONCLUSION}

Aneurysmal rupture is a devastating event, and is still a great problem for neurosurgeons all over the world. In developing countries, due to the obvious lack of resources for complex and expensive treatments required for the majority of neurosurgical diseases and particularities of each public health system organization, the overall results in the management of patients with intracranial aneurysm could be even worst. We work in two hospitals that care for a great number of patients sponsored by the public health system in Brazil. Over the time, it was possible to develop a referral pattern and protocols for a timely and adequate management of patients with subarachnoid hemorrhage, and to perform an adequate number of neurovascular procedures to maintain a well trained staff and allow for resident's trainning. We conclude that good results in the treatment of intracranial aneurysm are quite feasible, in spite of limited resources.

\section{REFERENCES}

1. Shaffrey ME, Shaffrey CI, Lanzino G, Kassell NF. Nonoperative treatment of aneurysmal subaracnoid hemorrhage. In Youmans JR (ED) Neurological surgery. 4.Ed., Philadelphia: Saunders, 1996:1264-1271.

2. Day AL, Morcos JJ, Revilla F. Management of aneurysms of the anterior circulation. In Youmans JR (ED) - Neurological surgery, 4.Ed., Philadelphia: Saunders, 1996:1272-1309.

3. Day JD, Giannotta SL. Posterior circulation aneurysms. In Youmans JR (ED) - Neurological surgery, 4.Ed., Philadelphia: Saunders, 1996:1335-1353.

4. Chyatte D. Diagnosis and management of aneurysmal subarachnoid hemorrhage. In Tindall GT, Cooper PR, Barrow DL (EDS) The practice of neurosurgery. Baltimore: Williams \& Wilkins, 1996:1989-1995.

5. Ho HW, Chander JP, Batjer HH Intracranial aneurysm: clinical manifestations. In Batjer HH. (ED) Cerebrovascular disease. Philadelphia: 
Lippincott-Raven, 1997:881-888.

6. Becker K. Epidemiology and clinical presentation of aneurysmal subarachnoid hemorrhage. In Winn HR, Le Roux PD. (EDS) Neurosurgery Clinics of North America, Philadelphia: Saunders 1998;9:435-444.

7. Schievink WI, Zabramski JM. Brain protection for cerebral aneurysm surgery. In Winn HR, Le Roux PD. (EDS) Neurosurgery Clinics of North America. Philadelphia: Saunders, 1998;9:661-671.

8. Le Roux PD, Winn HR. Management of the ruptured aneurysm. In. Winn HR, Le Roux PD. (EDS) Neurosurgery Clinics of North America. Philadelphia: Saunders, 1998;9:525-540.

9. Lanzino G, Kassell NF. Surgical treatment of the ruptured aneurysm timing. In. Winn HR Le Roux PD. (EDS) Neurosurgery Clinics of North America. Philadelphia Saunders, 1998;9541-548.

10. Kassell NF, Torner JC, Jane JA, Haley EC, Jr Adams HP, Kongable GL. The international cooperative study on timing of aneurysm surgery: Part 1 Overall management results. J Neurosurg 1990;73:18-36.

11. Kassell NF, Torner JC, Jane JA, Haley EC, Jr Adams HP. The international cooperative study on timing of aneurysm surgery Part 2 Surgical results. J Neurosurg 1990;73:37-47.

12. Osawa M, Hongo K, Tanaka Y, Nakamura Y, Kitazawa K, Kobayashi S. Results of direct surgery for aneurysmal subarachnoid haemorrhage: outcome of 2055 patients who underwent direct aneurysm surgery and profile of ruptured intracranial aneurysms. Acta Neurochir (Wien) 2001;143:655-663.

13. Bonilha L, Marques EL, Carelli EF, et al. Risk factors and outcome in 100 patients with aneurysmal subarachnoid hemorrhage. Arq Neuropsiquiatr 2001;59:676-680. 